\title{
Shanghai Sketch and the Illustrated City
}

\begin{abstract}
The Manhua Society was not just a matter of a few people coming together by happenstance. It was a product of the era. Behind it lay, first, the Northern Expedition and, second, the May Thirtieth Massacre. Several years of chaotic melee during the Northern Expedition together with the incursions of imperialist powers mobilized a group of patriotic young artists who aspired to use their talent to make a difference. Everyone felt a sense of gloom, and some were out of work. It was inevitable that they would come together.
\end{abstract}

The passage above comes from a 1980 interview with Wang Dunqing (1899-1990). Wang was a founding member of the Manhua Society, an important artist and theorist of manhua through the 1930s, and someone who had lived through the momentous historical events he mentions. As for the Manhua Society, its founding in late 1926 is recognized as a pivotal moment in the history of China's manhua art, mainly because from 1928 to 1930 a core group of the society's members, including Ye Qianyu (1907-95), Lu Shaofei (1903-95), and the brothers Zhang Guangyu and Zhang Zhengyu (a.k.a. Zhang Zhenyu, 1904-76), produced the illustrated magazine Shanghai Sketch. As manhua scholar and artist Bi Keguan observes, Shanghai Sketch "not only enriched artistic creation and cultivated talent, it also generated broad popular recognition and acceptance of the term manhua." The magazine's creators, asserts another scholar, "should be seen as the founders of a modern Chinese cartooning art." 2 And indeed, Ye, Lu, and the Zhang brothers worked steadily to develop and popularize manhua through the mid-193os on into the mobilization of manhua for propaganda during the anti-Japanese war years of 1937 to 1945 and beyond.

I open this chapter with Wang Dunqing's pronouncement on the Manhua Society because it tells one origin story for manhua, and I want to tell another. Wang assumes that the Manhua Society's members, and by implication the art they invented, were impelled by grand forces of history, in this case several landmark events in modern China's national narrative: the National Revolutionary Army's 
battles against regional militarists during the 1926-28 Northern Expedition, and the anti-imperialist strikes, boycotts, and demonstrations sparked by the killing of Chinese protestors at a Shanghai International Settlement police station in May 1925. When Wang links the motivations of the Manhua Society's members to these events, he makes manhua part of the narrative of modern Chinese national becoming. For Wang, manhua is historically important because it figured in the Chinese people's mission to free themselves from the double yoke of domestic and foreign oppression. As we will see in chapters 2 and 3, Ye, Lu, the Zhang brothers, as well as their many associates, did indeed take part in China's struggle against foreign invasion and domestic misrule, especially during the War of Resistance against Japan and through the ensuing Chinese Civil War. However, by assigning purely nationalistic motives to the founding of the Manhua Society, Wang's account suppresses an alternative story of manhua's emergence, a story distinct from the narrative of the nation-state. In this chapter, I argue that the two foundational moments in the consolidation of manhua-the formation of the Manhua Society and the publication of Shanghai Sketch-need to be rethought as elements of a "shadow history" bound up with quotidian urban experience in the everyday modernity of treaty-port Shanghai. To recapture that shadow history, we must return manhua to the primary medium of their publication and distribution, the pictorial magazine.

My approach to this question differs from existing studies in how it reconsiders manhua's emergence not just in pictorial magazines but as pictorial magazines. That perspective may appear unusual, but it is justified when we identify some key circumstances in the making of the Manhua Society and Shanghai Sketch. First, once we comb carefully through the historical record, it becomes clear that the members of the Manhua Society came together as makers of illustrated city serials rather than as cartoonists embarking on a patriotic mission. By that logic, it is a mistake to treat Shanghai Sketch as a cartoon magazine, despite the word manhua in its Chinese name, Shanghai manhua. Equally important, the magazine's English name, Shanghai Sketch, marks affiliation with the mass-culture print genre of the city magazine, a "new illustrated journalism" pioneered in the 189os on the pages of the London weekly called, not coincidentally, The Sketch: A Journal of Art and Actuality. The parallels between the two magazines obliges a rereading of Shanghai Sketch not as a landmark publication in the history of the Chinese cartoon but for how the magazine as a whole embodied the representational strategies of the urban-oriented illustrated magazine, making it a visual technology that engaged modernity through the serialized, heterogeneric representation of everyday city life. Shanghai Sketch, like its British counterpart, appealed to readers because it gave them a guide to "the spectacular consumption of the modern metropolis," helping city dwellers, many of them newcomers, to "negotiate the swiftly changing visual scene and to gain a sense of their place within it." ${ }^{4}$ Manhua was a part of that engagement, but only insofar as we rethink manhua in that historical moment as one element within the complex, interactive media artifact that was the city pictorial. 
My argument also asks that we view the city pictorial as part and parcel of the "everyday." I invoke that term to mean an experience of modernity understood "as ways of coming to terms with rapid technological change, urbanization, and capitalism as defining features of everyday life."5 As an illustrated metropolitan magazine, Shanghai Sketch was designed to respond to and shape the multitude of "daily gestures of production and reproduction" that constituted the micro-level negotiation of modernity, especially in the urban context. ${ }^{6}$ The magazine did this by presenting an ever-changing array of explicitly and implicitly connected textual and pictorial content. These varied materials were miscellaneous, but not random. They were laid out on the pages of Shanghai Sketch by a group of skilled editors and designers who knew well the mass appeal of a commodity able to make the modern city legible while also giving readers "a perception of communal knowledge" and "a comforting, pleasurable sense of a shared, if swiftly changing present."7 One can safely say that Shanghai Sketch did not sell cartoons about Shanghai; in fact, through most of its lifetime, the magazine hardly referred to any of its contents as manhua. ${ }^{8}$ Instead, it was a guide to what we might call the illustrated city, a manual for imagining and performing the modern in everyday Shanghai.

I develop this argument in several stages. First, I examine how Shanghai Sketch figures in the prevailing narrative of manhua's emergence, noting in particular how an anti-urban bias in this narrative points us to manhua's participation in a shadow history of the urban everyday that challenges the story of manhua's engagement with national history. Next, after a brief discussion of Shanghai Sketch's local and global genealogy as a popular illustrated magazine, I turn to the Manhua Society. Against accepted wisdom that the society devoted itself to developing the Chinese cartoon, I show how the activities of the society's members in fact circulated around the creation and design of urban lifestyle pictorials. From there, I move to Shanghai Sketch itself to demonstrate how manhua on the pages of this magazine cannot be reduced to single-panel cartoon drawings or sequential comics. Instead, just as Shanghai Sketch was a collaborative production by multiple artist-entrepreneurs, the art of the magazine comes into its own only when viewed as an interactive matrix of images and text designed to induct readers into the modern urban everyday. The chapter concludes with a rereading of the most famous regular feature in Shanghai Sketch, Ye Qianyu's famous Mister Wang (Wang xiansheng). Mister Wang has been celebrated as the first major Chinese comic strip but at the same time diminished as merely a representation of "petty urbanite" (xiao shimin) life. I argue that Mister Wang is best understood as working in concert with Shanghai Sketch's appeal to urban audiences, especially newly arrived "immigrants" to the city of Shanghai.

\section{RENARRATING MANHUA}

As a material object, Shanghai Sketch was an eight-page, large-format illustrated weekly released on Saturdays from April 1928 to June 1930. With a print run of 
110 issues and a distribution reportedly close to three thousand copies, the magazine achieved notable success in its namesake city's fiercely competitive print entertainment market. ${ }^{9}$ In any given issue of Shanghai Sketch, one could find written material, such as serial fiction, poetry, travelogues, film reviews, and assorted essays commenting on art, literature, and city life, crowded in alongside captioned photorelief images of current events, society men and women, architecture, female nudes, paintings, sculpture, and famous sites. These reproduced photographs in turn both complemented and competed with color and monochrome line sketches of subjects ranging from celebrity and social caricature to political satire and seasonal fashion. Interlarded throughout were copious illustrated advertisements for restaurants, cabarets, haberdashers, cigarettes, phonograph records, and patent medicines.

The content of Shanghai Sketch was broadly heterogeneous. But studies that refer to the magazine have tended to focus on its cover art, sketches, caricatures, comic strips, and so on-in other words, visually striking, cartoon-like content. For instance, as discussed in the introduction, Geremie Barmé judges the magazine for how its illustrations contrasted with Feng Zikai's understated, lyrical version of manhua. Doing so helps Barmé associate Feng with a modern Chinese independent intellectual tradition distinguished from the vulgar opportunism of urban mass culture, represented by the "fringe commercial artists" of Shanghai Sketch, whom he describes as monopolizing and sensationalizing manhua to gain "a viable niche in the commercial art and magazine market." ${ }^{\circ}$ Other scholars adopt a more positive view of the magazine by foregrounding its modernist visual aesthetic. Lynn Pan associates the creators and contents of Shanghai Sketch with a cosmopolitan "Shanghai style" that flourished during the interwar years. ${ }^{11}$ Paul Bevan treats Shanghai Sketch as a forum for introducing Euro-American artistic modernism, the influence of which, he argues, put manhua on par with the canon of the Chinese modern art that emerged around the same time as manhua, through the 1920 s and 1930s. ${ }^{12}$ Ellen Johnston Laing also approaches Shanghai Sketch through the lens of modernism, but she emphasizes links between the magazine's visual art and a simultaneous current of literary modernism in the form of the decadent and the neo-sensationist schools of writing. ${ }^{13}$

What unites all these very different studies is how, in various ways, they react against Bi Keguan's largely negative assessment of Shanghai Sketch. Writing during the 1980 s under the influence of Maoist aesthetics, which valued art and literature that advanced a left-populist, anti-imperialist political agenda, Bi's history of China's manhua disparages Shanghai Sketch precisely because of the influence of decadence and modernism. The magazine's infatuation with imported modernist styles, he argues, prevented the art and artists of Shanghai Sketch from expressing opposition to the imperialist and colonialist forces that were holding China back from its destiny as a nation-state. With the exception of the contributions of Huang Wennong (1903-34), who specialized in political and current affairs cartoons, as well as several isolated examples of socially critical manhua by other contributors, 
Bi dismisses the rest of the magazine as an immature, aberrant stage in manhua's evolution. The late 1920 s was, he asserts, a time when the magazine's young artists, enamored with the modish, decadent eroticism of Aubrey Beardsley's line drawings, were capable of little more than depicting "surface appearances" and "vulgar slapstick" that as Bi puts it, failed "to deeply reflect the essence of the era's social life" or "truly exercise the remonstrative effect of manhua." 14

Bi's position on Shanghai Sketch is worth examining because it is premised on the idea of the Chinese nation-state as the subject of history. For Bi, contribution to the nation determines the value of art, such that manhua as an aesthetic form has value only insofar as it engages the grand narrative of national struggle by motivating people to identify with and perform that narrative. Manhua, in other words, must function as nationalist pedagogy. Or as Bi puts it, manhua must remonstrate with its audience, educating them, awakening them, and mobilizing them for a higher national purpose. Bi Keguan was, of course, not the first to saddle the arts and literature of modern China with such a mission. Creating art and literature to forward the project of the nation was a founding principle in the reinvention of Chinese culture from the turn of the century onward. It was articulated in the reformist intellectual Liang Qichao's instrumentalist conception of fiction as a shaping force for a modern citizenry, carried forward in May Fourth period (1919-23) authors' advocacy of "art for life's sake," retooled by left-wing writers and artists in the 1930s, and amplified during the War of Resistance period, especially at the communist base in Yan'an, where in 1942 Mao Zedong instituted the program of state-sanctioned art by and for the Chinese masses that became aesthetic orthodoxy under the People's Republic of China after 1949 and on into the 1980s, when Bi wrote his history.

Clearly, Bi Keguan's critique of Shanghai Sketch fell in line with mainstream ideological orthodoxy. But he was far from the first to take the magazine to task for questionable content. Around fifty years before Bi published his study, manhua artists themselves felt the need to write manhua into the national narrative. Examining how they did so reveals an ambivalence toward Shanghai Sketch as, at one level, a city magazine but, at another level, an alternative mode of experience grounded in the urban everyday rather than the project of nation.

One of these early artists was Wang Zimei (1913-2002). Wang's 1935 article "China's Manhua: Evolution and Prospects" laments the failure of manhua's readers and practitioners to recognize this art as something able to engage the "evolution of the era" (shidai de yanjin)_Wang's veiled way of referring to the Chinese nation's struggle against multiple types of domestic and foreign oppression. ${ }^{15}$ Against that background, manhua remains a promise yet to be fulfilled: "Born and bred in an era demanding progress, manhua made its unwholesome debut in a culturally dilapidated China. Despite some hard-won successes over the short period from its early beginnings to the present, manhua has yet to achieve the overall standards that would grant it value and status in its own right. 
Consequently, people do not sympathize with or support manhua as an emergent art form because they fail to recognize its core ideology and value. As it has been fashioned in China, manhua remains a novelty item."16

Manhua, then, is a victim of China's own ideological backwardness. Wang implies that manhua can come into its own only when imbued with significant content able to heighten political awareness. His assessment of Shanghai Sketch is largely positive but also carefully qualified, and it reveals as well an ambivalence toward urban culture. On the one hand, Wang affirms Shanghai Sketch's importance to manhua as the publication that, after years of "haphazard manhua-like creations," at last "officially declared the intent and purpose of manhua," guiding readers "to enter a new realm of amusement and forget the old entrenched ways." But Wang also tactfully questions the consciousness (yishi) of the magazine's artists (who by 1935 were influential editors at the publications where Wang published his own work) as "many sided" (duojiaoxingde). They were, he elaborates, "brimming with fin-de-siècle morbidity as they dissected the diseased entrails of the metropolis and described the bewitching allure of women-the influenza of modern times." "' "Upon more serious examination," Wang continues, "these artists were naturally at a stage where they had yet to objectively experience the central issues of the era, with each of them chasing rainbow fantasies to cultivate the attractions of technique."18

In a companion piece to Wang Zimei's article, the left-leaning manhua artist Huang Shiying (fl. 1930-37) conveys a similar agenda. Rather than assessing the consciousness of the artists, however, Huang describes manhua as a direct expression of history. "The manhua published by artists of any given era," he writes, "contain the political circumstances and social conditions of their time," such that "reviewing manhua of the past is no different from reading a history of economics or social evolution, or a running account of political events." The historical nature of manhua encourages Huang to map manhua's development onto a series of major national-historical occurrences: the 1911 Republican Revolution's overthrow of the Qing dynasty, the 1919 May Fourth Movement's "cultural revolution," the anti-imperialist foment sparked by the May Thirtieth Massacre of 1925, and the national trauma caused by the 1931 Japanese invasion of Manchuria. ${ }^{19}$ This chronological approach is, of course, the same as that taken up by Wang Dunqing and later expanded by Bi Keguan and others in historical surveys of manhua. ${ }^{20}$ Manhua's supposed predisposition to reflect history makes Huang's account much more sanguine than Wang's, and Huang in fact asserts confidently that "manhua has won the sympathy of a broad readership." Yet even as Huang celebrates the inventiveness of the manhua in Shanghai Sketch, he echoes Wang Zimei when he attributes the magazine's attraction for urban readers to the way its artists "delighted in depicting the morbidity of city life."

Wang Zimei, Huang Shiying, and later Bi Keguan all agree that Shanghai Sketch was a foundational moment in the development of manhua. They also agree that 
manhua acquire significance only when tied to the historical narrative of modern China as a nation, by either expressing the "era" or raising readers' awareness of the outstanding issues of the times. The general verdict on Shanghai Sketch, delivered in historical hindsight by all three critics, is that it succeeded only partially as a vehicle for manhua's proper development, the reason being that manhua art published in Shanghai Sketch was unable to sufficiently engage history because it appealed to its readership with a form of experience-modern and urban-that was incompatible with the experience of "the era," or in other words, the ongoing historical story of the Chinese nation. In short, the city is an impediment to progress. It is as if manhua cannot find its true identity as a nation-centered art form precisely because of its affiliation with the modern city, a place tainted with shallowness, frivolity, disease, death, and unbridled sexuality.

The belief that manhua must be delivered from the degeneracy and corruption of the art's host city, Shanghai, draws power from the archetypal image of the "city of darkness" prevalent in the literary and cultural imagination of the time. ${ }^{22}$ The problem, however, lies not with the salvational story these commentators invoke but with the construction of manhua as if it were a character in that story, a discrete entity seeking its true path in life. But when Shanghai Sketch was first published in 1928, manhua was not, so to speak, manhua. That is, manhua had yet to be acknowledged as a freestanding genre of pictorial art. It was not, in and of itself, a "thing." Instead, manhua at this stage in China referred less to cartoons per se than to the visual technology of the pictorial magazine, or huabao. These magazines, for their part, were mass-cultural media objects bound up with the modern, urban everyday. The everyday, as discussed at the beginning of this chapter, was a form of experience that ran counter to the story of nation imposed on the invention of manhua in Shanghai during the late 1920 .

Put another way, Shanghai Sketch was not simply a vehicle for manhua but an example of the hybrid, mass-oriented visual technology of Shanghai's pictorial press. Studies of Shanghai's pictorials as media objects have variously described them as emblematic of the modern experience in interwar Shanghai for how they functioned as "kaleidoscopic" "visual emporiums of cosmopolitanism"; ${ }^{23}$ sites able to "conjure up a collective imaginary" of modern urban life; ${ }^{24}$ and interactive "arenas of cultural work and process" that responded to and guided everyday practice of their audience's "periodic life routines." ${ }^{25}$ These magazines, in other words, were an integral part of what historian Harry Harootunian has, in the context of interwar Asian metropolises, described as "an unprecedented expansion of new cultural and representational forms supplied by new technologies, diverse artistic experimentation, film, photography, photomontage, documentaries and novels depicting the experience of daily life and more that called attention to both an historical moment and the foregrounding of everyday life as the ground of history." ${ }^{26}$

As heterogeneric, image-text media objects defined by their miscellaneous, topical content, pictorial magazines like Shanghai Sketch appealed to readers 
precisely because their hybrid content incorporated the full range of these "new cultural and representational forms," from fashion and current event photography to film and theater advertisements, casual essays and serial novels, and, of course, multiple styles of line drawing. Pictorials, in short, packaged and spectacularized the mundane noise and distraction of the urban everyday as a mass-produced, widely circulated commodity. Similar to what Vanessa Schwartz has described for late nineteenth-century Paris, "The visual representation of reality as spectacle ... created a common culture and a sense of shared experience through which people might begin to imagine themselves as participating in a metropolitan culture because they had visual evidence that such a shared world, of which they were a part, existed." ${ }^{27}$ Put another way, the representation of everyday life in pictorial magazines like Shanghai Sketch invited readers into an alternative mode of historical experience, one in which they themselves featured as agents.

That mode of experience challenged-or "shadowed"- what was at the time an increasingly dominant imagination of history structured by nation-state ideology. Important here is the difference between the experience of the urban everyday in cities like Paris, Berlin, London, and New York and in Asian metropolises, such as Tokyo, Bombay, and Shanghai, where capitalist modernization arrived via the external agencies of Euro-American imperialist and colonialist regimes. Thus, even though the developed parts of interwar Shanghai looked much like any other modern city to judge from phenomenal surfaces - the high-rises, the department stores, the cinemas, the motorcars, the trains, the electric lights, the array of commodities displayed in shop windows, and so on-the everyday experience of the urban modern had a very different inflection for those Shanghai residents who, politically and socially excluded from the city's colonial power structures, constituted its subaltern population. In Shanghai and Tokyo, just as in Paris and Berlin, the specific textures of the urban everyday grew into a locus of interest, observation, and analysis. But in the Asian cities, meaningfully registering the urban everyday became a historical problem of contesting temporalities and agencies. The issue was

how best to account for (and represent) what was occurring in the present, not what had happened in the past. This entailed forging a present of one's own that would become a past in place of a practice in which another's past dominated the present. The experience of capitalist penetration under the sign of modernization and a new temporality called "modernity" meant that the lived reality of the everyday by the masses was different from the nation and its narrative telling people how to fulfil its requirements for national subjectivity and citizenship. If the nation composed a narrative of enactment by the people, the everyday of the masses wrote a vastly different history of its own. ${ }^{28}$

The modern, mass-produced, urban illustrated magazine, a print genre introduced to Asian metropolises simultaneous with the expansion of capitalism and colonialism, was a key media form in defining, elaborating, and quite often celebrating this other temporality. ${ }^{29}$ As serial publications designed to represent and 
interpret, through word and image, the ongoing ephemera of modernity, pictorials provided "an optic through which to account for the experience of a phenomenal present." ${ }^{\circ}$ As a typical pictorial of its time and place, Shanghai Sketch was much more than a vehicle for cartoon art. It was a hybrid media object embedded in and engaged with the urban modern, a form of visual technology that generated new structures of understanding that on the surface entertained and informed but at the same time generated a vision of time, history, and agency that countered totalizing narratives of nation.

\section{GENEALOGY}

All this may seem a heavy burden to place on the shoulders of popular illustrated periodicals and the fun, entertaining, little drawings they carried. Yet the metaphors of urban morbidity and corruption leveled against the art featured in Shanghai Sketch suggest the danger that manhua seemed to represent. To go a step further, that danger derives at least in part from how city magazines like Shanghai Sketch generated an interpretive community distinct from the imagined community of the nation-state. As Benedict Anderson has famously argued, the spread of print capitalism generated one of the conditions for nationalist consciousness through the mass-production and distribution of print artifacts, like the novel and the newspaper, able to create a sense of simultaneity among readers who otherwise had no tangible connection to one another. ${ }^{31}$ That potential sense of shared time and belonging could be turned to the purposes of nation-state pedagogy, that is, the broad-based construction of people who imagined themselves first and foremost as constituents of a modern nation. But community could be imagined in other ways. Illustrated city magazines also emerged within the conditions offered by print capitalism, but they helped create a form of shared identity grounded in the presentoriented everyday culture of the modern city..$^{32}$ As Gerry Beegan writes, London's The Sketch was a "metropolitan commodity, produced in the city, and intent on evoking the metropolis in a new way." ${ }^{33}$ It did so by means of new photomechanical print technologies whose ability to economically combine halftone photographs and line sketches with light, topical writing about city life met the desires of a growing urban middle class, or "six-penny public," and as mentioned above, created a shared sense of agency and identity among these city dwellers.

Scholars of Shanghai print culture have, largely in passing, noted the construction of this kind of shared everyday urban experience through the city's early illustrated periodicals, most significantly the late nineteenth-century Dianshizhai Pictorial (Dianshizhai huabao, 1884-98). Richard Wagner has pointed out how Dianshizhai, due in part to its unprecedented attention to "the common man and woman," "was the first clear articulation of the aesthetic preferences of the new urban classes, which developed in conjunction with similar preferences in Western and Japanese urban centers." ${ }^{34}$ Roberta Wue develops that view, noting 
how the "great subject" of Dianshizhai, and of its most prolific illustrator, Wu Youru, "may be that of the anonymous urban crowd" whose "lively agency . . . is shared by readers of the magazine." ${ }^{35}$ Even the left-leaning manhua artist Huang Shiying recognizes that Dianshizhai, despite what he points to as the backward "feudal-era" tendencies of its illustrations, was the "earliest ancestor of the Chinese pictorial magazine" as well as the "starting point for the illustrated depictions of actual social life." ${ }^{36}$ It is significant, too, that Huang's history tracks manhua's evolution not just alongside historical events but also in tandem with Shanghai's popular press, from Dianshizhai through a chronological sequence of illustrated newspapers and magazines. The kinds of publications Huang cites emerged in symbiosis with the burgeoning growth of urban leisure entertainment through the city's late Qing and early Republican periods. ${ }^{37}$ What all this implies is that even though The Sketch may have lent Shanghai Sketch its foreign name and its model of city journalism, the Chinese magazine must also be seen as coming out of Shanghai's own genealogy of local illustrated papers, from Dianshizhai's lithographically reproduced, traditional-style line drawings accompanied by hand-lettered commentary to the crowded image-text mosaics of typeset daily broadsheets like China Camera News and on to a host of full-length monthly magazines featuring lavishly colored covers. Shanghai Sketch was not, in other words, invented out of thin air as a publication devoted to manhua, but nor was it a mere imitation of its British namesake. It was, rather, one among many competing serials in Shanghai's entertainment press during the mid- and late 1920s, all of which to some degree incorporated cartoon-style drawings.

\section{RETHINKING THE MANHUA SOCIETY}

Locating Shanghai Sketch within a genealogy of local pictorials rather than treating it as simply a vehicle for manhua art helps pry manhua away from the conventional, nation-centered narrative. The same can be said for the Manhua Society. Shanghai Sketch is presumed to be a publication project of the Manhua Society, with the society itself understood as an artistic association motivated by patriotic, anti-imperialist sentiments and events. The society's main activities, meanwhile, have been described as promoting the Chinese cartoon by "officially introducing the term manhua to China, and elevating the standards of manhua art through investigation of theory and technique." ${ }^{38}$ That narrative, however, begins to come apart once we take a closer look at the formation of the society and the making of Shanghai Sketch, not from the perspective of manhua's historical development but from the angle of publishing pictorial magazines.

First, it is important to note that the members of the Manhua Society came together for largely commercial purposes. In doing so, they followed what Christopher Rea has identified as a "collective enterprise" model, in which a group of cultural entrepreneurs combines financial and creative resources to pursue a 
shared goal, in this case, the publication of a magazine. ${ }^{39}$ The society specifically presented itself as one of the many art associations that proliferated in Shanghai during the early Republican period. As Pedith Chan has observed in the context of "national painting," or guohua, these associations were primarily a practical means for newcomers to the Shanghai art world to establish social and professional networks that would give them entrée to the city's growing, and increasingly competitive, commercial market for art. The public manifestos (xuanyan) inaugurating these societies, Chan adds, typically expressed high-minded aesthetic and social goals, although the actual activities of members centered on marketing and selling their art. ${ }^{\circ}$ When we turn to the manifesto of the Manhua Society, first published in December 1926, we do indeed see a promotional announcement boasting a lofty, though rather vague, mission:

Recently, drawing clubs have been established like flower buds in the spring, like the surging tides in autumn. Does this herald a bright future for the arts, or the ambition to rule the roost through strength in numbers? Nobody can say for sure, but in the case of our little group, we've come together purely out of mutual interest and ambition, with each and every one of us relying on our innate abilities, intelligence, and experience to express "our romanticism" through art for the sake of advancing the human mind. In other words, we want to make this human society of ours into new soil for the tiller. Whether or not the products of our "heart and blood" will be recognized as artistic labor, and whether or not they will meet our ideals, are questions impossible to fathom at this moment. Yet it is our hope-though not our pledge! - to work together to plant good seeds in this time of artistic immaturity. In the future, when it comes time to reap the fruits of our labors, probably not a single member of our group will be willing to go forth and enjoy them. ${ }^{41}$

The manifesto's authors do not elaborate on what is meant by "our romanticism" or what they envision for "a new land." Nor do they spell out how using manhua in their society's name differentiates them from other art societies, though elsewhere they describe what they do, with teasing ambiguity, as "vastly different" (jiongyi) from other art associations. ${ }^{42}$ In fact, we learn more about the society's artistic mission from its street address, a third-floor room on the corner of Ningbo Road and Zhejiang Road in downtown Shanghai. Starting in early 1926, this location was also the shared office address of two pictorial papers, China Camera News and Shanghai Life (Shanghai shenghuo, 1926-27). ${ }^{43}$ As discussed in the introduction, China Camera News was an entertainment broadsheet, heavily illustrated with sketches and reproduced photographs, published every three days under the editorial hand of Zhang Guangyu. Zhang had launched China Camera News in August 1925 to compete with Pictorial Shanghai, which he had worked on for a month as an editor alongside two other founding members of the Manhua Society, Wang Dunqing and Ding Song (1891-1972). ${ }^{44}$ Shanghai Life, a monthly that released just four issues between July 1926 and June 1927, was managed by a team of three coeditors, two of whom-Lu Shaofei and Huang Wennong-became 


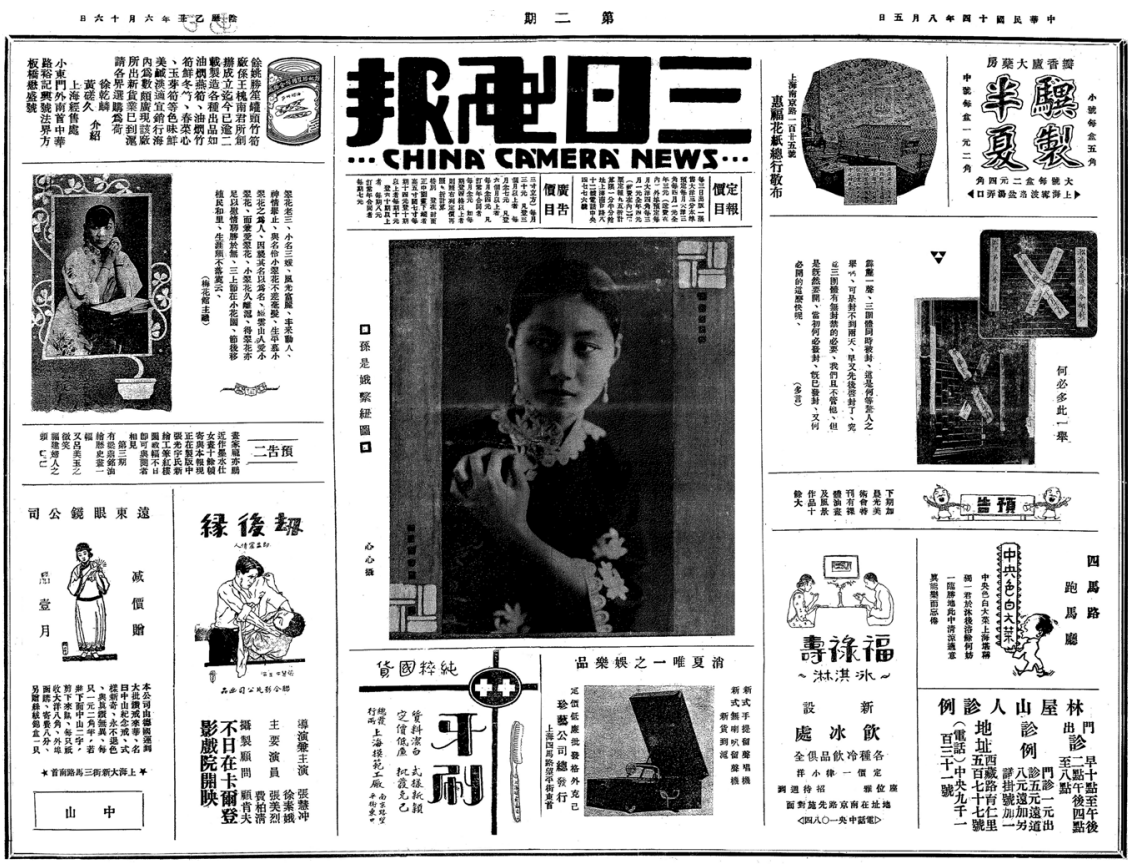

Figure 6. Front page of the August 5, 1925, issue of China Camera News.

Manhua Society members as well. ${ }^{45}$ Not surprisingly, given the shared workspace, contributors to both publications overlapped and included other members of the Manhua Society, such as Ye Qianyu, Hu Xuguang (1901-60), and Zhang Guangyu's younger brother, Zhang Zhengyu. ${ }^{46}$

Another feature of the Manhua Society that leads one to question the centrality of manhua to its activities is that nowhere in the society's manifesto or in other contemporary accounts of society meetings do we see manhua mentioned as a specific focus of activity. Instead, the manifesto refers only to members' "works of art" (yishu zuopin).47 In comparison with contemporaneous guohua societies, whose manifestos often quite specifically promoted traditionalist painting as a national art form to be preserved and developed, the Manhua Society was unusually nebulous in focus. ${ }^{48}$ That very ambiguity, however, may have been a result of the diverse, improvised nature of the artistic production that had brought the society's members together, namely, materials to fill the pages of their popular illustrated serials. Any given issue of China Camera News included many different kinds of photorelief pen-and-ink drawings, such as political cartoons, celebrity caricatures, social caricatures, illustrations for serial fiction, fashion sketches, charcoal portraits, picture puzzles of Peking opera characters, and, especially on the front page, advertisements (many of them signed by the society's members) for restaurants, phonographs, wallpaper, and canned foods, to name a few (see figures 6 and 7). Even more prominent, as one would expect from the word 


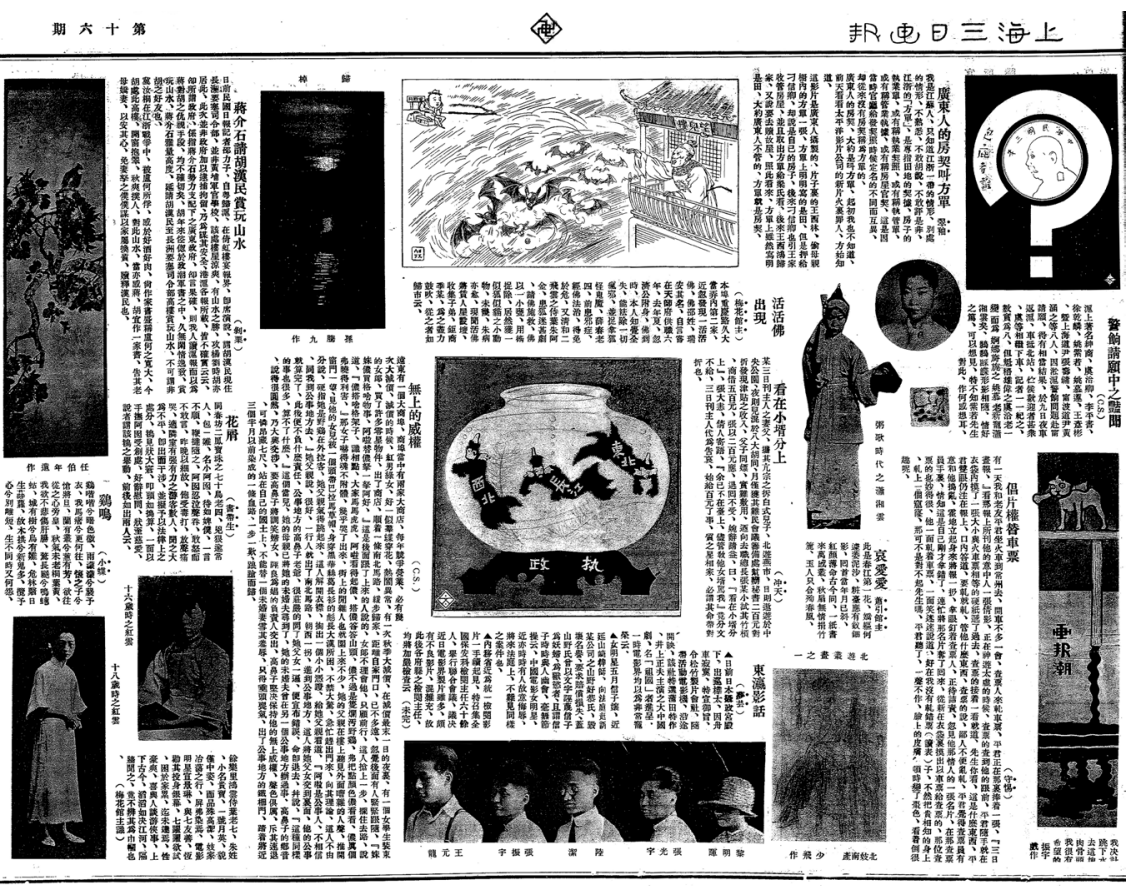

FIGURE 7. The back page of the September 16, 1925, issue of China Camera News. The photograph at bottom center pictures Zhang Guangyu (second from right) and his brother Zhang Zhengyu (Zhenyu, fourth from right).

"camera" in the tabloid's English-language name, were half-tone prints of photographs, often on subjects with aspirations to high art, such as landscape, contemporary guohua, and female nudes, as well as items from the local entertainment world, such as promotional film stills, portraits of courtesans, and photographs of traditional opera actors and actresses, not to mention the occasional shots and sketches of China Camera News' own editors and contributors.

Considering the actual nature of the output of the Manhua Society's members, then, one can say that if the society was committed to a specific genre, it would not be manhua per se but the print genre of the pictorial, with the latter understood as a work of urban commercial art incorporating text and image. When it comes to understanding the society's artistic goals, we are better off looking past the platitudes of the manifesto and instead considering the way the society's members represented their publications to potential readers. We see this most clearly in the publication announcement for China Camera News' companion publication, Shanghai Life. Printed in the Shanghai newspaper Shenbao in May 1926, the announcement claims to reproduce the text of an open letter that the editors of Shanghai Life sent to two hundred writers and artists within and beyond Shanghai, spelling out for them, and for readers of Shenbao, the inspiration behind the magazine: 
The great metropolises of Europe and America, such as London, New York, and Paris, all publish lifestyle magazines [miaoxie shenghuo zazhi] that offer interesting observations and keen critique on the topics of clothing, food, and shelter, expounding on everything related to issues of everyday living [rensheng riyong wenti], and popularizing them around the globe as soon as they are released. With this in mind, we have established the monthly magazine Shanghai Life, thus venturing to apply our meager abilities toward describing social phenomena while resolving the issues of clothing, food, and shelter in this flourishing East Asian city and cultural center of China, Shanghai, a place teeming with daily news items big and small. ${ }^{49}$

Based on the content of China Camera News, and later Shanghai Sketch, we can treat this announcement as a statement of the primary artistic mission of the society's members. In other words, the practical work of the Manhua Society centered on creating and distributing a mass-produced lifestyle magazine modeled after similar publications in major Euro-American cities but self-consciously grounded in the urban everyday textures of Shanghai. It would not be amiss to say that with Shanghai Life and China Camera News, the society's members promised readers a guide to the "art" of everyday life-how to dress, eat, and dwell-in a global, cosmopolitan city.

Here it is also worth pointing out how the mixed motivations-lofty in spirit but commercial in practice - that informed the Manhua Society's efforts can be seen in the society's emblem, a stylized dragon coiled within a heavily drawn circle (see figure 8). There are, in fact, two versions of the logo. One was reportedly carved as a seal by society member Zhang Meisun (1884-1975) at the recommendation of Wang Dunqing in November 1927 at the last formal meeting of the society and later printed on the cover of the first volume in the society's book series, Huang Wennong's Satirical Drawings (Wennong fengcihua ji)..$^{50}$ An earlier version of the logo appears in the December 25, 1926, issue of China Camera News, surrounded by the text of the society's manifesto (see figure 9). The later, 1927 emblem is the one reproduced in standard histories of manhua, where it receives an allegorical interpretation as the awakening dragon that is modern China, thus providing evidence, as one commentator puts it, for "Manhua Society members' identification with the destiny of the country." ${ }^{11}$

The version printed in China Camera News is similar enough to yield the same nationalistic interpretation. It is, however, executed with a small but telling difference. Drawn in sharper relief against its white background, the China Camera News dragon quite plainly has just three legs, thus calling to mind a less prestigious but widely popular mythical creature, the chanchu, or "wealth-beckoning toad," a folkloric animal believed to attract money. Given that the society's members trafficked in carefully coded humorous visual messages and that such messages proliferated on the pages of China Camera News, the money-making connotations of the emblem would most likely not have been lost on either the society's members, who were immersed in the task of turning a profit by publishing pictorials, or readers, whose coins fed the open-mouthed beast every three days. 


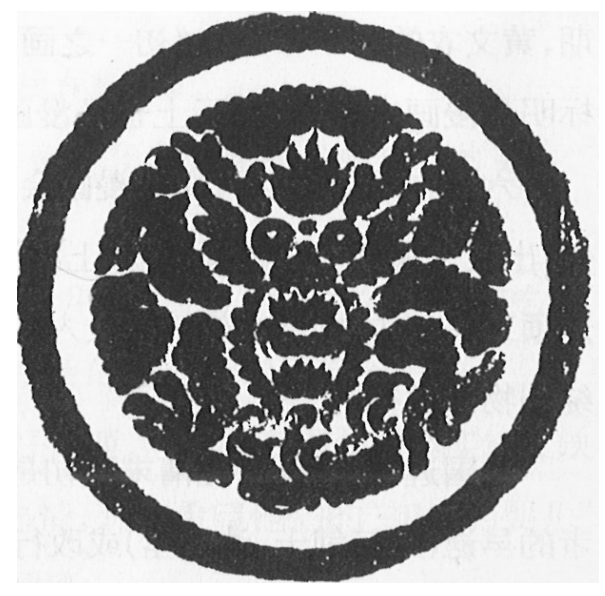

FIGURE 8. The Manhua Society emblem as designed by Zhang Meisun in 1927.

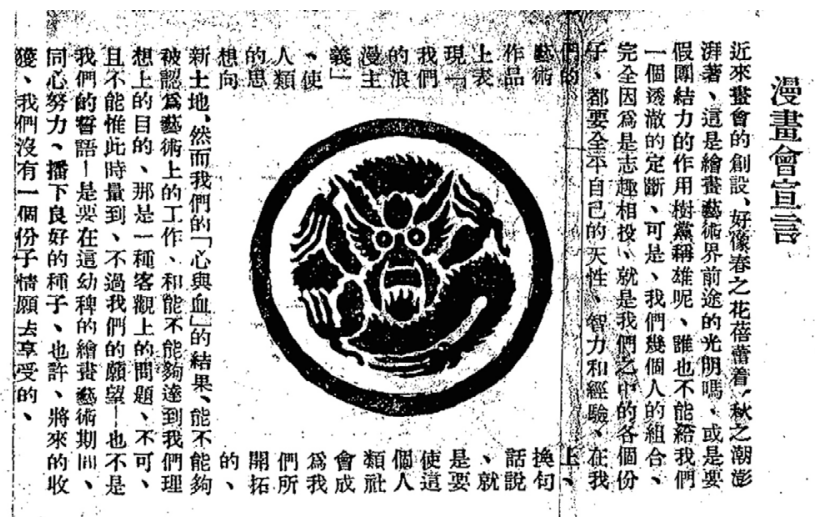

FIGURE 9. "Manifesto of the Manhua Society" with the society's emblem, from China Camera News, no. 158 (December 1926).

\section{THE ART OF THE PAGE}

Given that the Manhua Society's members initially coalesced around the publication of China Camera News and Shanghai Life and that their primary artistic pursuit was designing and creating content for these illustrated city pictorials, it makes sense that their most significant single project was another, more ambitious, magazine: Shanghai Sketch. As I have already stressed, treating Shanghai Sketch merely as a source for "cartoons" diminishes understanding of what manhua meant at this time. It is better, I argue, to examine how the society's members as a collective constructed manhua within the dynamically heterogeneric milieu of the illustrated city pictorial. In other words, the "art" of the Manhua Society was the illustrated magazine, and these magazines functioned as a visual technology designed to guide readers' experience of and identification with the urban everyday. As Gerry Beegan observes, "the unique power of the illustrated magazine was its ability to quickly and continually circulate the knowledge that city dwellers needed" by juxtaposing text and image issue after issue in extended series. ${ }^{22}$ 
Beegan explores how in the 1890 s, the British weekly The Sketch amalgamated newly available technologies of photorelief image reproduction with various kinds of textual content to reinvent the illustrated newspaper for London's city dwellers. The editors of Shanghai Sketch similarly experimented with creative recombination of text and image. Their most notable innovation was applying the limited technology available at the time to enrich the hybrid contents of the magazine with color printing. Specifically, Shanghai Sketch merged color lithographic printing, suited to brightly colored drawings and advertisements, with copper-plate printing, amenable to laying out typeset text alongside the more familiar monochrome photo-relief halftones and line sketches. Shanghai Sketch was thus like two magazines in one. As we can see in Ye Qianyu's recollection of the production process, the color and monochrome pages were designed and laid out separately, with the four color pages printed first on one side of a sheet of paper at one printing facility and the remaining four on the reverse at another:

Aside from the weekly comic strip Mister Wang, at Shanghai Sketch I was also tasked with designing the layout for pages four and five. It was just Zhang Guangyu, Zhang Zhengyu, Huang Wennong, and Lu Shaofei providing the drawings. I would collect them inside of three days, paste them onto the proofing plate, and along with the cover and page eight comic strip, send everything off first to the print shop to be photographed and reduced, and then to the lithography studio to prepare the color plates. During the two days it took to do the four-color processing, I would bring the four edited copperplates for pages two, three, six, and seven, as well as the written manuscripts, to the letterpress printer for typesetting. Friday evening I would take the printed color manhua sheets to the letterpress. Usually we wouldn't go to print until around 10:00 p.m., and the job would be finished around sunup, when I would immediately hire a vehicle for delivery to the newspaper vendors on Wangping Street. For five days I was hustling between the two print shops. Sometimes I helped the craftsmen at the lithography press trace the stone plates, and when Friday afternoon rolled around I had to go to the letterpress printer to do typesetting with the workers there, laboring through the night until daybreak Saturday to get the magazine to Wangping Street. ${ }^{53}$

Ye spells out the steps involved in shepherding Shanghai Sketch from content creation and layout through printing and distribution. Downplayed in his account, however, is the cooperative effort behind producing the magazine. Collective decision-making would have been inevitable given that the office of Shanghai Sketch on Shandong Road comprised just one room that had to serve as space for "editing, publishing, sales, eating, and sleeping, as well as a bookshop," according to Xuan Wenjie, who began work at the office in early 1928 as an errand boy. ${ }^{54}$ Xuan also relates how editorial tasks were done in rotation by all the main contributors, with page formats (banshi) hung on the wall, the layout penciled in, authors' names confirmed, and content decided on by everyone before it was pasted up. ${ }^{55}$ 
Shanghai Sketch's fast-paced, collaborative production process prompts us to reconsider the magazine's aesthetic qualities. For instance, taken individually, most of the panels on the color pages are rather unremarkable. As Bi Keguan puts it, the manhua of Ye Qianyu, Zhang Guangyu, Lu Shaofei, and others as found in Shanghai Sketch were still at "an unstable stage of experimentation" derivative of Western models and weakly defined in terms of personal style. ${ }^{56}$ Bi's observations are not inaccurate. His concern with development and imitation, however, is informed by a teleological view of manhua as a discrete genre developing along a certain aesthetic and ideological trajectory, namely toward a distinct national identity and consciousness. Once we approach the art of Shanghai Sketch as creative collaboration, organized by the more immediate visual interactivity and hybrid aesthetics of the pictorial, the standards of judgment change drastically.

The point of departure for this more holistic approach relates to the fundamental appeal of illustrated city magazines: their ability to create and enhance the shared culture of a metropolitan community by meeting readers' desire to see and know themselves and their fellow urbanites. Photomechanical techniques enhanced this appeal by augmenting "media's ability to portray the modern crowd to itself." techniques mainly comprised the application of photo-relief process to reproduce two categories of imagery: photographs and line sketches. These were, in fact, precisely the two types of materials requested by the editors of Shanghai Sketch. The call for contributions (zheng gao) printed in an early issue of the magazine invited readers to send in photographs (zhaopian) and drawings (huagao), with the latter broken down into categories of satirical (fengcide), fashion (xinzhuangde), comic (huajide), decorative pattern (tuiande), and lifestyle (miaoxie shenghuode). ${ }^{8}$ The four monochrome pages of issues of Shanghai Sketch adhered to a standard scheme that featured halftone prints of photographs interspersed with pen-andink sketches and accompanied by blocks of explanatory typeset text, making that portion of the magazine quite similar to its predecessor China Camera News and any number of competing Shanghai tabloids. Meanwhile, the color pages, which included the front cover, were, as we know from Ye Qianyu's account, printed separately using four-color chromolithographic process. The color pages featured pen-and-ink sketches as well as hand-drawn advertisements.

Whether color or monochrome, the reproduced images in Shanghai Sketch contrasted with and complemented one another. "The photograph," as Beegan observes, "in particular the photographic portrait, was used by magazines to support the emphasis on subjectivity that was one of the central characteristics of the new illustrated journalism. This focus on the personal applied to the content of the magazines, which concentrated on human interest and celebrity." 59 The penand-ink sketch, meanwhile, was regarded as "a radical new art form able to portray contemporary life directly to a modern audience unfettered by academic conventions. The sketch was characterized as an immediate, subjective impression, its 
speed and authenticity attested to by the supposed autographic qualities of process reproduction. These sketches gave magazine readers a reassuring sense that the city and its denizens were knowable, legible. Rapid minimal sketches were deployed in the press as the antithesis to the overdetailed, static photograph."60

Both these forms of reproduced images "signified modernity" for readers of the time. ${ }^{61}$ Not to be ignored was another late nineteenth-century innovation: the incorporation of image-based advertising. The placement of advertisements in and around the regular text and image content of the illustrated magazine represented the beginning of "a new commercial alignment in which the product became an integral part of the periodical and the illustration was used as a means of stimulating mass consumption." ${ }^{2}$

We can get an initial, if necessarily partial, idea of how these multiple features of the illustrated magazine came together in Shanghai Sketch by exploring the structure of a page of color sketches, in this case the fifth page of issue number 72 , published September 7, 1929 (see figure 10). The artwork here is typical in its focus on city life in Shanghai, the thematic center of gravity for the magazine as a whole. Standard practice when dealing with Shanghai Sketch and related publications has been to single out individual works according to how, for instance, they reflect certain stylistic influences or communicate specific beliefs and attitudes of the time. I would argue, however, that we learn more by treating individual works as parts of an interactive matrix wherein individual panels are, to varying degrees, structured into a nonsequential, composite work contained by the "metapanel" of the page. ${ }^{63}$ We have, in other words, a multiauthored collage, designed not as a discrete, independent work of art but as an interactive vernacularization of everyday gestures and consumption patterns built into the format of a serial publication.

The assemblage in figure 10 responds to and guides viewers' desire to construct a modern identity in and through the urban everyday. In the absence of narrative sequence, one can, of course, begin anywhere on the page. The eye is naturally drawn, however, to the relatively large center frame, an untitled diptych presenting a dapper young man-about-town. Neither humorous nor political, the panel is perhaps best classified as what the magazine's editors in their calls for submission referred to as a "fashion" (xinzhuang) sketch. What makes this particular sketch interesting is the high density of markers of modern urban time and space contained within it. For instance, the inserts in the upper-right and lower-left corners, which read "Saturday" and "Sunday," respectively, locate both panels' action within the consumption-oriented leisure activity allowed by the modern, urban temporality of the work-free weekend. As a weekly published on Saturdays, Shanghai Sketch was itself aligned with this segmentation of everyday time, lending the panel a purposeful, self-referential link to the time of the immediate present.

The drawing foregrounds the space of modernity with equal, if not greater, intentionality. The right-side panel presents a modern interior: an upscale Western-style café, where the young man dines on what appears to be ice cream 


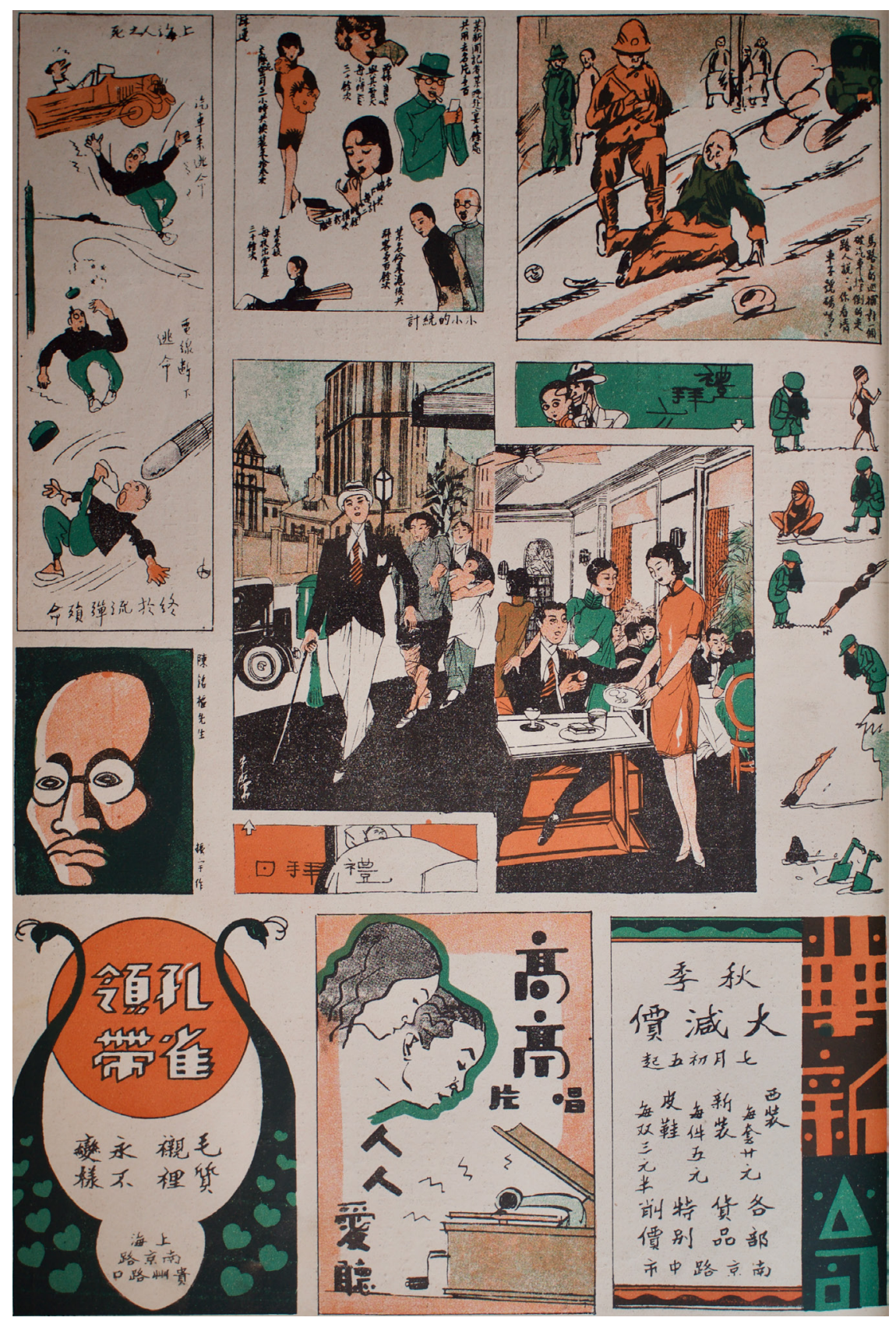

FIGURE 10. A color page from Shanghai Sketch, no. 72 (September 7, 1929). 
and sandwiches while doted on by two stylishly dressed, professionally attentive waitresses. The panel on the left depicts the same man, now outdoors, striding confidently along one of Shanghai's main boulevards, possibly in the fashionable French Concession. Of particular note here is how the artist has associated the young man with multiple symbols of urban modernity: to his immediate right, an automobile and a post box; behind him, a high-rise building; and over his left shoulder, a streetlamp. Not to be overlooked are a middle-aged mother and her wet nurse. Their drab clothing, shapeless figures, and subordinate position behind the male figure seem contrived to accentuate his sartorial masculinity, while also serving as foils for the sexual allure of the waitresses in the opposing panel. ${ }^{64}$

The cartoon, if we can call it that, depicts a certain idealized male agency performed in the milieu of Shanghai modernity. Yet any reading of this drawing is incomplete without accounting for its interdependence with the matrix of images, organized into discrete panels, immediately surrounding it on the metapanel of the page. These images include several humorous social caricatures along the top and sides, a small celebrity caricature on the left, and three advertisements along the bottom. These images, along with the accompanying text, form a complex ensemble able to engage readers' desires to perform and participate in an everyday urban community, to experience, like their counterparts reading similar magazines in London or New York, a sense of "knowingness" based on "up-to-date knowledge of a broad range of ephemeral, contemporary material." 65

To begin with the drawings in the right and left top corners of the page, we see a pair of classic urban social caricatures, both in implicit dialogue with the central panel. On the left, Huang Wennong's "Death of a Shanghainese" ("Shanghai ren zhi si") shows a man dodging first a speeding car and then a loose electric cable before being killed by a stray cannon shell. On the right, Lu Shaofei's untitled sketch depicts another encounter with urban hazards, showing a man who has been knocked down by a passing car and then stumped by a policeman's request for the license plate number. Little more than raw slapstick when viewed in isolation, these two sketches form a stark contrast with the central panel's selfassured, nattily dressed young man, who, quite unlike his bumbling counterparts dressed in stodgy traditional outfits, seems to glide effortlessly through the technologies of modern life. Readers are, of course, encouraged to identify with the man in the central frame and thus imagine themselves as members of a knowing, worldly group of urban sophisticates.

The page's interpanel dialog does not end there, however. If the social caricatures in the top two corners set off the ideal of urban masculinity, the advertisements for menswear occupying the bottom two corners guide readers toward emulating that ideal in actual life. The Huaxin haberdashery ad on the lower right, for instance, announces an upcoming fall sale featuring discounted Western-style suits and dress shoes, while the more decorative panel on the left touts Peacock Neckties (Kongque lingdai). As it happens, all these items of apparel-suit, shoes, striped 
necktie-feature prominently on the person of the smart-looking central male character, who, we might imagine, equipped himself at these very shops. Attiring oneself in the same style would require no more than a trip to Nanjing Road, guided by the addresses written into the advertisements.

Moving back to the top of the page, we encounter an example of a multifigure social caricature entitled "Little Statistics" ("Xiaoxiao de tongji"). The panel enumerates the everyday excesses of a collection of Shanghai "types," such as a "Western lady" (xifu) named Mary who kisses her pet dog every two minutes, a journalist who collects over one hundred name cards from attending a dozen dinners in one night, and a social butterfly called Miss S. who changes her outfit thirteen times an hour. Caricature arrays of this sort featured regularly in Shanghai Sketch, as they did in London's The Sketch. Humor certainly accounts for much of their popularity in both cities. But just as important, if not more, was how the fragmented style of drawing captured the rapid flux of human activity in the city while also reassuring viewers "that the urban masses were recognizable and categorizable." ${ }^{66}$ Readers could, with a smile, imagine their own place among the myriad classes and characters of what could be an overwhelming city.

The three remaining panels - a celebrity caricature, a five-panel pantomime comic, and an advertisement for Odeon Records (Gaoting changpian) - appear completely unrelated. Each, however, works in its own way to generate an underlying sense of knowingness for readers. The caricature, drawn by Zhang Zhengyu, portrays regional militarist Chen Mingshu (1889-1965), who in 1929 was governor of Guangdong Province. ${ }^{67}$ The significance of Zhang's drawing lies not in its choice of celebrity, nor in the style in which it is rendered, but in how this subgenre of sketch, the celebrity caricature, provides readers with a shared knowledge of "public personalities," that is, "individuals that everyone knew," and around whom they could coalesce as an imagined collective. ${ }^{68}$

Across from Zhang's caricature, the comic running down the right margin shows a fashion journalist whose pursuit of photos of women in swimsuits leads to clownish misfortune. The interest of this drawing lies not so much in its facile humor as in its visual parody of the magazine's photographic content. The creator of this unsigned sequence pokes fun at the photographer's work but at the same time creates an autoreferential relationship to the magazine by inviting readers to a "behind the scenes" look at the making of the pictorial magazine. The sense of knowingness thus created is augmented by editors' and readers' awareness of these publications' sometimes blatant dependence on photographic portraits of women, especially young celebrity and society women, to boost sales. Shanghai Sketch's own monochrome pages were heavily populated by such images, taken in the studio or outdoors, often of nudes presented in the name of art or science. The five-panel comic parodies this media obsession with the female figure. But it also refers more immediately to several preceding late summer issues of the magazine that registered a new vogue for swimming by presenting photographs of young 
women poolside and on the beach. ${ }^{69}$ Regular readers would comprehend that the joke was, in fact, on Shanghai Sketch itself as a typical, mildly exploitative panderer of the female image. To go a step farther, one can argue that the photographer is caricatured as well. Shanghai Sketch's cameramen were far from anonymous. Nearly every reproduced photograph included a byline, and the magazine made a point of promoting photographers by publishing reviews of their exhibitions, advertisements for their studios, and images of the photographers themselves. ${ }^{70}$ The image-makers thus participated in the cult of celebrity their images generated. A comic sketch of a photographer who comes to grief due to a visual fixation on women is, then, more than a simple sight gag. It derives its appeal as much, if not more, from a sly wink directed at a community of readers familiar with the production practices, and promotional excesses, of Shanghai Sketch.

Finally, the advertisement for Odeon Records located bottom center points to another everyday community of consumption: recorded music. The ad's tagline, "Everyone loves to listen" (ren ren ai ting), just below the heads of a young couple hovering intently over a gramophone, points to the making of what historian William Kenney has called "active recorded sound cultures"-in this case, a Chinese version of the "circles of resonance" that characterized the reception of the mass-produced $78 \mathrm{rpm}$ record. ${ }^{71}$ According to Kenney, the dissemination of mass-produced musical messages in the early twentieth-century United States created new public cultures of consumption based in sound and characterized by "widely shared patterns of popular behavior, thought, emotion, and sensibility" that generated new forms of historical experience..$^{72}$ The same phenomenon occurred in interwar China, where transnational corporations such as Pathé-EMI quickly adapted their products to appeal to local urban audiences and recorded music's perceived potential to alter popular sensibilities made it a site of cultural contention. The ideological positions in play over popular music align with those guiding discourse on manhua. Nationalist ideologues on both the right and left promoted musical styles thought to discipline citizens into performing a national narrative of unity and resistance. They defined that position vis-à-vis a degraded "other" just entering the market in the mid-1920s: the popularly appealing "yellow music," a racially tinged, city-based hybrid of folk forms and foreign jazz commercially propagated through the technologies of phonograph, radio, and film, in partnership, of course, with the entertainment press. ${ }^{73}$ The advertisement for Odeon, with its enticement to enter a community of informed music consumers, thus joins its companion panels on the page as an element of the "remaindered excess" of the urban everyday that evaded, and antagonized, the national idea. ${ }^{74}$

None of the drawings on this particular page of Shanghai Sketch are particularly remarkable for their artistry or subject matter. Most, like the center diptych and the advertisements, would not even qualify as manhua according to later definitions of that word. The point, however, is not to hunt through the forest of cartoon-like imagery found in Shanghai Sketch to identify individual drawings that exemplify 
certain desired features of a pictorial genre in the process of emergence. It is, rather, to open our eyes to how the print genre of the pictorial allows for the loose but purposeful assembly of images and text into an interactive, dialogic imagetext that invites and guides readers into the time and space of the modern urban everyday.

\section{MISTER WANG AND THE URBAN IMMIGRANT}

The most extensive representation of the urban everyday in Shanghai Sketch can be found in its celebrated comic strip Mister Wang. Created by Ye Qianyu, who was at the time twenty-one years old, Mister Wang greeted readers in the first issue of Shanghai Sketch on April 21, 1928 (see figure 11). The strip appeared weekly during the two-year run of the magazine with only a few brief interruptions and rapidly gained a strong following that made it the most important and longest-running early Chinese serial comic, as well as the forerunner of other celebrated strips that emerged in the 1930s, such as Huang Yao's Niubizi and Zhang Leping's (1910-92) Sanmao. After Shanghai Sketch was absorbed into its successor magazine, Modern Miscellany (Shidai, 1929-37), in 1930, Ye continued to publish Mister Wang, as well as spin-offs of the original strip, in Modern Miscellany and other pictorials and several newspapers until war with Japan broke out in 1937.75

Mister Wang deserves recognition for its artistry, longevity, and popular appeal. The strip can also be read as a prime example of how the illustrated city magazine mediated the shadow history of the urban everyday. Such a renewed understanding of Mister Wang starts by recognizing the influence of foreign models on the strip. In a general sense, Mister Wang borrowed the graphic style of pen-and-ink caricature that had emerged in the new illustrated journalism of the 1890 s as a "sketchy aesthetic that evoked the rapidity of modern life." ${ }^{76}$ More specifically, as Paul Bevan has observed, Mister Wang imitated the Sunday color edition of George McManus's Bringing Up Father, published in the 1920s by the English-language Shanghai newspaper China Press (Dalu bao). ${ }^{77}$ Bevan emphasizes the degree to which Ye Qianyu, like his colleagues in Shanghai's commercial art circles, constructed their art by emulating overseas publications. In terms of storylines, characters, and even panel composition, the similarities between Bringing Up Father and Mister Wang are indeed striking. Beyond surface appearances, however, it also matters that Ye modeled Mister Wang after McManus's strip, whose main character, the nouveau riche Irish immigrant Jiggs, attempts to navigate various modern and typically urban social situations. Ye Qianyu's genius lay not in copying the American comic but in localizing for a Shanghai audience what Robert C. Harvey identifies as the central theme of Bringing Up Father: the "culture shock" of the immigrant experience, the rapid and "disorienting . . rise from rags (metaphorically speaking) to riches (ditto), from the poverty of the Old World to the relative prosperity of the New." ${ }^{78}$ In the case of Mister Wang, the readers were immigrants as well, but 


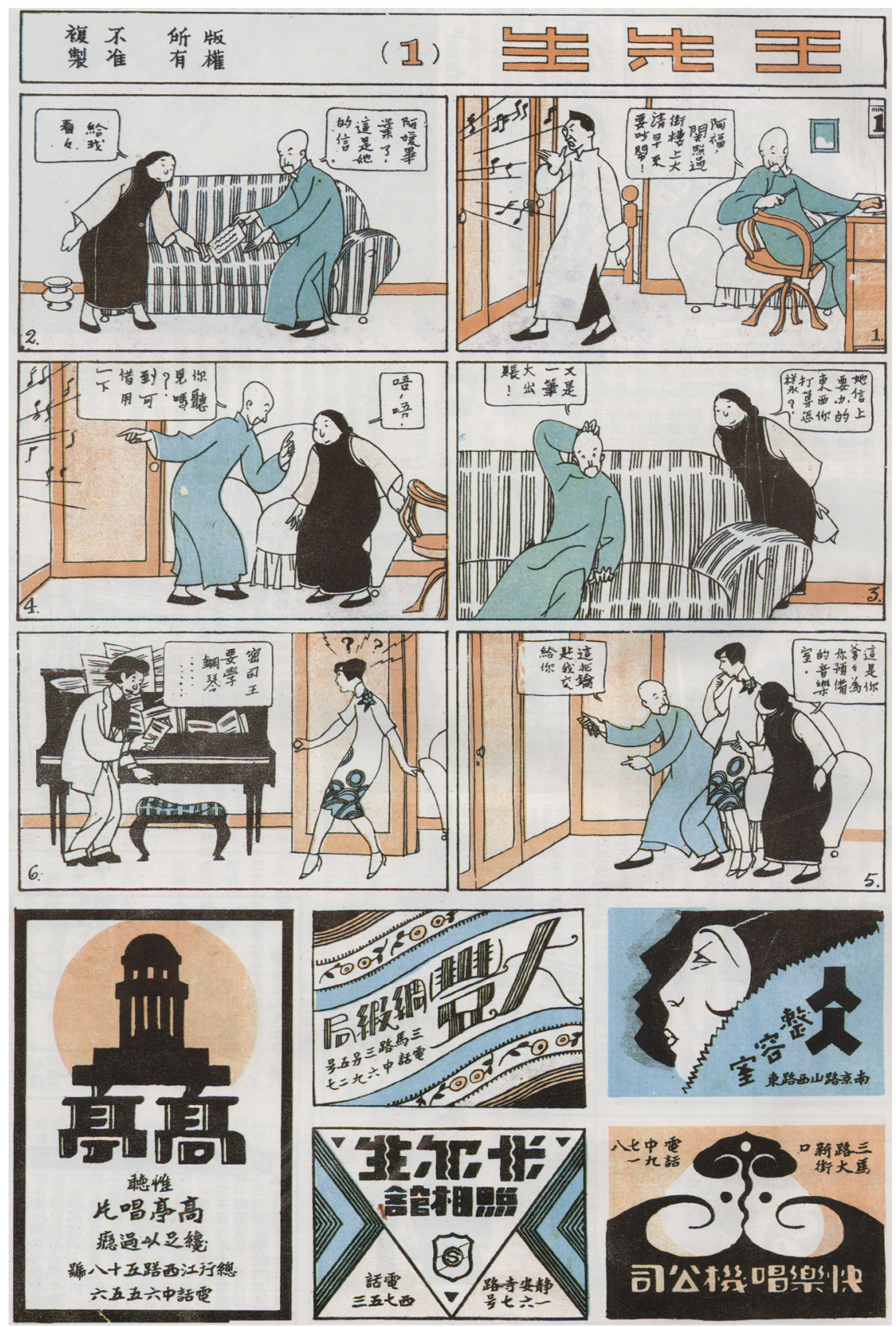

FIGURE 11. The first installment of Mister Wang, published in Shanghai Sketch, no. 1 (April $21,1928)$. Mister Wang attempts to avoid the cost of buying a new piano for his daughter by introducing her to a tenant who is a musician. 
internal immigrants, recent arrivals in China's own "new" and quite foreign world of metropolitan Shanghai.

It is no coincidence, then, that Mister Wang's household has the means to avail itself of all the modern pleasures that interwar Shanghai had to offer, including a single-family alleyway townhouse, a private automobile, outfits in the latest fashions, and the leisure time to patronize restaurants and nightclubs and take pleasure trips by rail to seaside resorts and tourist meccas. Mister Wang's weekly misadventures made readers laugh but also guided them through an ideal, imagined lifestyle of a typical Shanghainese, or shanghairen - and indeed, Shanghairen was nearly chosen as the strip's title at its inception in 1928. ${ }^{79}$ A description of the strip by Ye Qianyu's younger brother, Ye Gang (1919-2004), suggests the degree to which Mister Wang represented the time and space of urbanites' everyday lives to urbanites themselves through the form of the comic sketch:

Most of the plotlines in Mister Wang are social in nature, its distinguishing feature being the depiction of the varied ephemera of everyday experience. Social trends, plucked casually from the flow of life, are turned into stories. From springtime outings to enjoying a snowfall, from dining with friends to gambling parties, from the city streets to the countryside, from luxury hotels to pavilion rooms, from big community events to private affairs of one's children, on down to idle gossip about neighbors. Just about any and every little place and event gets depicted in ways that are comical but not abusive, amusing but never crude, and appealing to every kind of taste, making for a daily must-read for everybody that, if skipped for a day, leaves one with the feeling of having missed out. ${ }^{80}$

Mister Wang entertained its audience with gags and slapstick. At the same time, it attracted readers with its detailed and timely simulation of everyday Shanghai. Ye Gang's appraisal of Mister Wang resonates with what Vanessa Schwartz identifies as "one of the pleasures of modern life," namely, "the collective participation in a culture in which representations proliferated to such an extent that they became interchangeable with reality." ${ }^{1}$ The permeability of representation and reality found in Mister Wang was in part driven by unrelenting deadline pressure. As was the case for the early, presyndication years of the first successful American comic strip, Bud Fisher's Mutt and Jeff, Ye Qianyu drew Mister Wang for publication just before it hit the newsstands. Producing a strip under such circumstances "permitted extremely topical and local comedy: the cartoon in today's paper could be based upon the news in yesterday's paper." ${ }^{82}$ But where Fisher linked his strip to the daily horse races in San Francisco, Ye Qianyu ran his weekly strip in continuous dialogue with Shanghai Sketch's own representations of everyday life, from fashion and commodities to cultural events and all manner of leisure-time pursuits.

Mister Wang's change in clothing style, which occurs very early in the lifetime of the strip, points to the underlying theme of immigrant self-transformation. He first appears to readers wearing a Chinese-style man's long gown, melon-skin cap, 
and cloth shoes. By issue 9, in preparation for a promenade in Shanghai's French Park, he dons for the first time what will become his trademark look in Shanghai Sketch: a Western outfit of trousers, suitcoat, and necktie (see figure 12). Within the strip, Mister Wang's change in apparel is prompted by his stylish young daughter, who invited him on the outing, which comes to grief in an auto accident. But as with the fashionable young man-about-town from issue 72, discussed above, Mister Wang's modern makeover aligns with the magazine's regular advertisers, in this instance the ABC and Huaxin clothing shops, whose ads are placed at the bottom of the page.

Such links to everyday commodities do not end with the Mister Wang character. Mister Wang's daughter invariably appears in outfits indistinguishable from those Ye Qianyu and other magazine staff illustrated for Yung Zong (Yunshang) brand women's apparel. Also, Miss Wang's hair, as well as that of Mister Wang's partner in vice Young Chen, is carefully shaded (see figure 13) to mimic the sheen promoted by another weekly sponsor of the magazine, Hairstick pomade (see figure 14). The reproduction of fashion imagery in the Mister Wang strip is not surprising given that Ye Qianyu had been producing such sketches for Shanghai serials since December 1926, when he was designated fashion editor for Shanghai Sketch's predecessor, China Camera News. ${ }^{83}$ But as Mister Wang matured, the strip gradually incorporated more of the products and services advertised in the magazine. For instance, the type of equipment promoted weekly by Chiyo Yoko Photo Supplies (Qiandai yanghang) figures in a strip where Mister Wang purchases a new camera while on an outing to Hangzhou. Advertisements for local restaurants like Happy Forest (Kuaihuo lin) and nightclubs like Moon (Yue gong) remind readers of installments where Mister Wang opens his own Family Cafe (Jiating shipin gongsi) at Christmas time and celebrates his first Western-style New Year's Eve party at a dance hall. ${ }^{84}$ Furthermore, Mister Wang and Young Chen were not content to stay confined to their strip. About seven months into the publication run of Shanghai Sketch, Wang and Chen began to populate the magazine's regular advertisement for Yantai Beer, placed right below the Mister Wang comic itself (see figure 15). Once the formula was set, the pair also showed up in promotions for Bianli brand dry-cell batteries and Huamei electrical appliances.

It was not just products and personalities that circulated between the strip and the magazine's advertisers; the stories in Mister Wang also frequently echoed the magazine's regular content. One of the earlier strips shows Mister Wang holding his own solo art exhibition; the same issue, two pages later, includes a full-page illustrated write-up of an exhibition of watercolor and charcoal sketches, held that very same weekend, by several of Shanghai Sketch's contributing artists. ${ }^{85}$ A strip printed the following Saturday, about Mister Wang's fumbled encounters with foreigners in a public park, recalls a photo-essay published just two issues before introducing the parks in Shanghai's foreign concessions. ${ }^{86}$ In the same vein, 


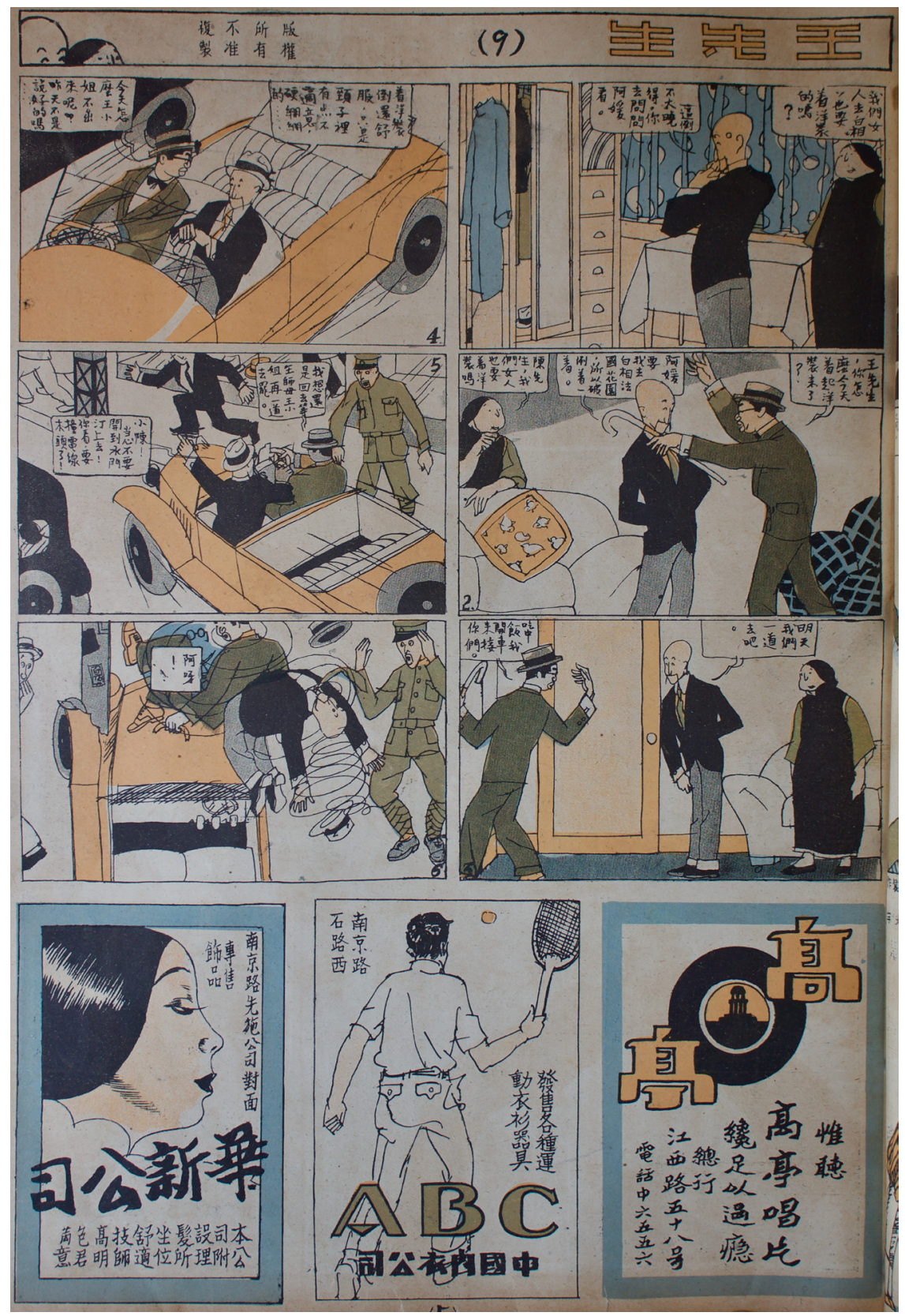

FIGURE 12. Mister Wang tries on Western clothes for the first time. Shanghai Sketch, no. 9 (May 16, 1928). The panel sequence in this comic is vertical, starting from the top right. 
FIGURE 13. A panel showing the sheen of pomade in the hair of Young Chen and Mister Wang's daughter. Shanghai Sketch, no. 10 (May 23, 1928).

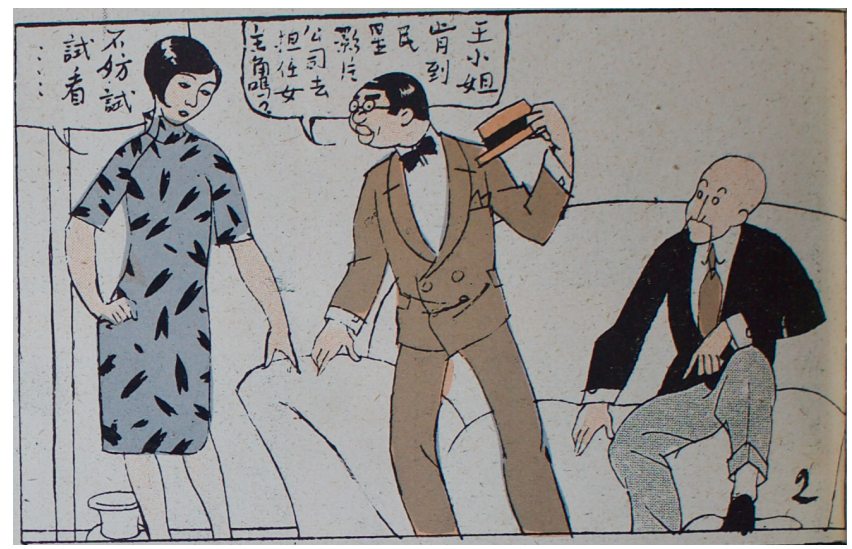

FIGURE 14. An advertisement for Hairstick pomade. Shanghai Sketch, no. 10 (May 23, 1928).

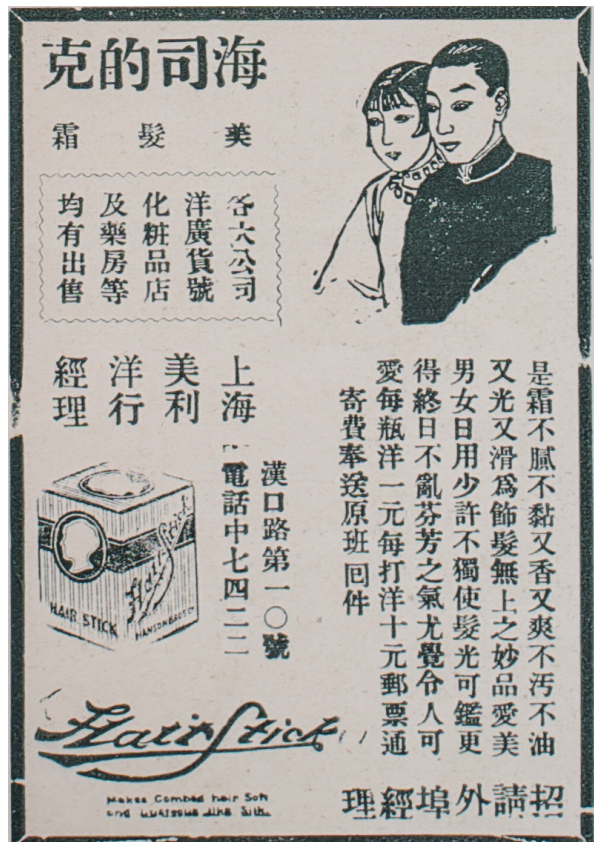

a Wang family trip to the seaside on the nearby island of Putuo in the July 27, 1929, issue (see figure 16) shows men and women frolicking on the beach much as young vacationers are represented the very next week in a photo spread from the seaside city of Qingdao (see figure 17). Particularly elaborate is the mirroring of comic storytelling and lifestyle reportage going on between a seven-installment strip following the Mister Wang cast of characters during a tour of Hangzhou's scenic 


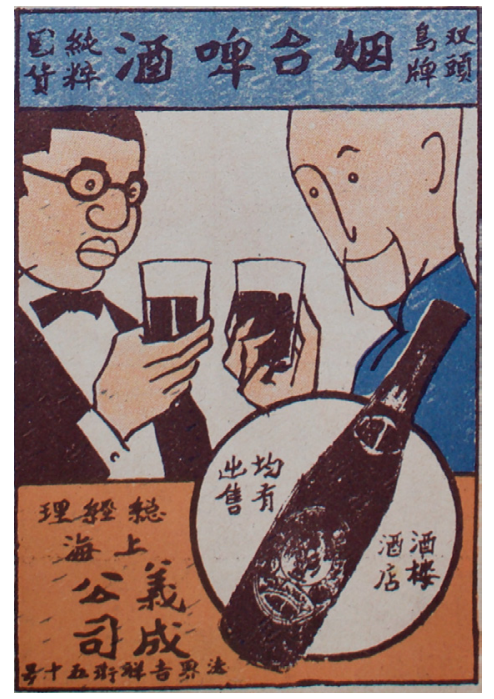

FIGURE 15. Mister Wang and Young Chen in an advertisement for Yantai Beer. Shanghai Sketch, no. 39 (January 12, 1929).

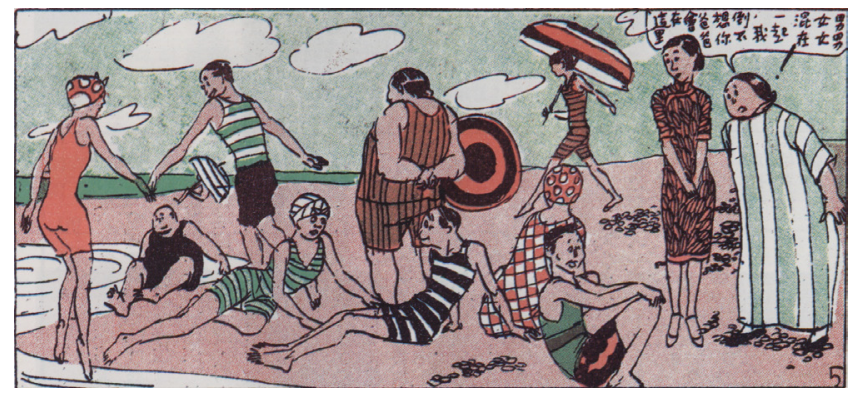

FIGURE 16. Mister Wang and his family at the beach. Shanghai Sketch, no. 66 (July 27, 1929).

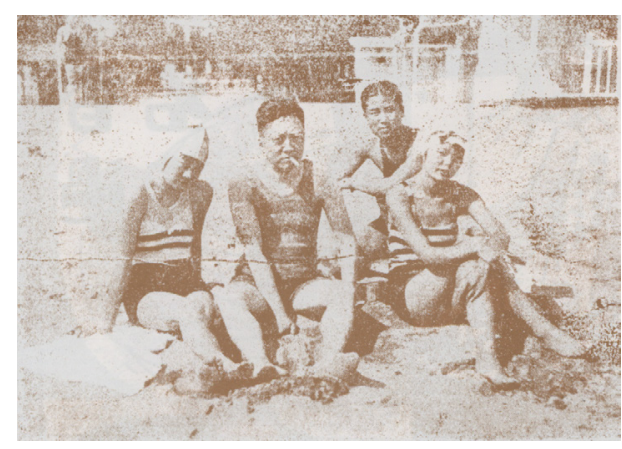

FIGURE 17. A photograph of young beachgoers at Qingdao. Shanghai Sketch, no. 67 (August 3, 1929).

West Lake and, six weeks later, a three-part travel feature by Ye Qianyu and Zhang Zhengyu describing a trip to the very same locale. ${ }^{87}$ The real-life junket of Ye and Zhang revolves around boating and banquets rather than pratfalls and gaffes, but both narratives model the middle-class pursuit of leisure-time travel. 
FIGURE 18. Miss Shao Qi'an in Hangzhou. Photograph by Ye Qianyu. Shanghai Sketch, no. 39 (January 12, 1929).

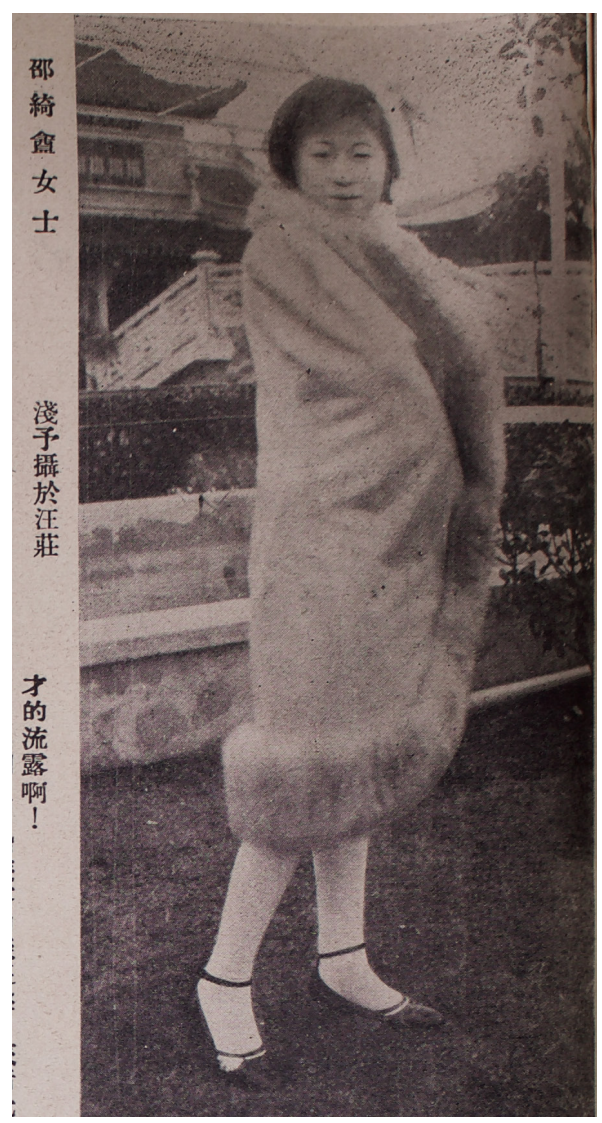

One might ascribe such resonances between comic-strip fiction and lifestyle journalism to coincidence. However, Ye deliberately plays with this overlap. For instance, in the Hangzhou travelogue, he points to the interpenetration of representation and reality when he includes his own photograph of a female companion, Miss Shao Qian (see figure 18). It is a shot of Miss Shao posing in a new fur-lined cloak. Miss Shao, Ye informs us, would often tailor her own clothes after Ye's fashion illustrations in Shanghai Sketch. And indeed, the cloak Miss Shao wears in the picture matches precisely a fashion sketch by Ye that had appeared on the cover of Shanghai Sketch two months earlier (see figure 19), an issue that, coincidentally, featured the Wangs and Chens in the midst of their fictional visit to Hangzhou. ${ }^{88}$

Ye Qianyu takes such play even further by embedding the print medium of the pictorial magazine in Mister Wang's comic storylines. In the strip's fortieth installment, for example, Mister Wang discovers himself held up as the butt of jokes in a copy of Shanghai Sketch peddled to him on the street (see figure 20). 


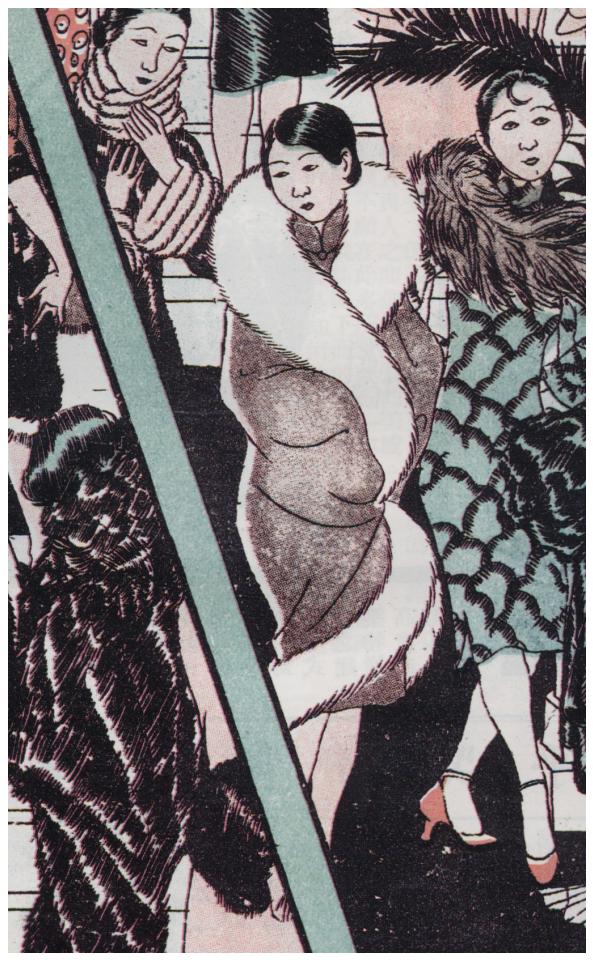

FIGURE 19. Detail of cover art by Ye Qianyu showing Ye's sketch of the cloak worn by Miss Shao Qian in figure 18. Shanghai Sketch, no. 30 (November 10, 1928).

Indignant, he teams up with Young Chen to bring a trio of hoodlums to the offices of the magazine to seek compensation for defamation of character. The magazine's editor (who bears a vague resemblance to Ye's colleague, Zhang Zhengyu) promises to print an apology as long as Mister Wang continues to provide him with material. The matter appears settled until Mister Wang and Young Chen find their wives enjoying complimentary copies of Shanghai Sketch that had been sent to their homes. The strip's last frame then zooms in to a captioned "photograph" printed in the magazine the womenfolk are reading. Drawn to match one of the earlier panels in the strip, it reports on a person "claiming to be Mister Wang" of the popular comic strip leading a gang of toughs to the Shanghai Sketch office. ${ }^{89}$

A similar instance of self-referential humor appears in one of the later issues of Shanghai Sketch, published shortly before the magazine was absorbed by Modern Miscellany. Here, Wang and Chen partner to publish their own pictorial, titled Tiny Pictorial (Xiaoxiao huabao). When the first issue, featuring cover photographs of the comic strip's five main characters, fails to sell, Young Chen quickly boosts circulation by packing the front page with exploitative photographs of young women, including several nudes..$^{90}$ Given that Shanghai Sketch printed nude images of women in nearly every issue, readers of the time could hardly have missed the irony. 

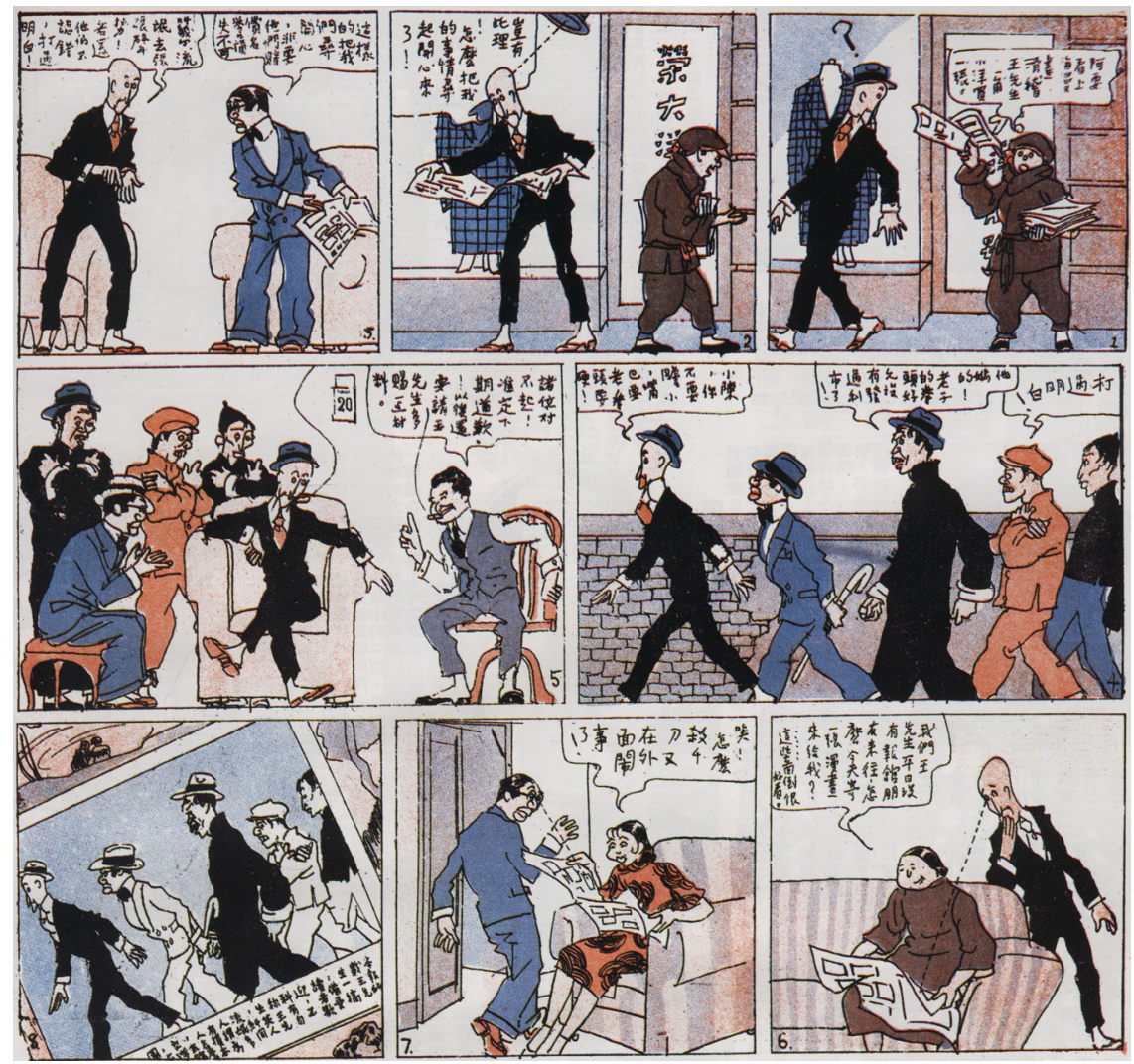

FIGURE 20. Mister Wang's run-in with the editorial staff of Shanghai Sketch. Shanghai Sketch, no. 41 (January 26,1929$)$.

A more subtle and pervasive feature of Mister Wang, and what set Ye Qianyu's signature creation apart from any other strip of the time, was his attention to the details of everyday life in Shanghai. Ye immerses his strip in the flow of city experience. Not only do the characters wear the latest fashions, but their clothes change with the seasons, from overcoats and furs in the winter to short-sleeved shirts and cheongsams in the summer. When it snows in Shanghai, it snows in Mister Wang. When the July heat is unbearable, Mister Wang sweats and suffers, too. When a meningitis epidemic hits the city, the characters wear hygienic masks. Ye Qianyu embellishes indoor spaces with sofas, desk chairs, wall clocks, bedclothes, telephones, tea sets, thermoses, balusters, table lamps, throw pillows, and spittoons, all in the designs of the day (see figure 21). Out on the street, the strip's cast of characters shuffles and fusses against a background of the urban ephemera that gave Shanghai, and its residents, a sense of their own place in the world: ornamental ironwork, carved lintels, postboxes, doorknobs, dustbins, advertising banners, 


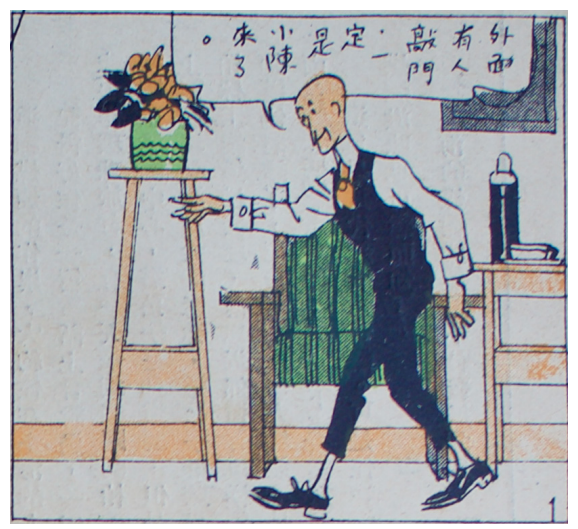

FIGURE 21. Mister Wang at home.

Shanghai Sketch, no. 71 (August 31, 1929).

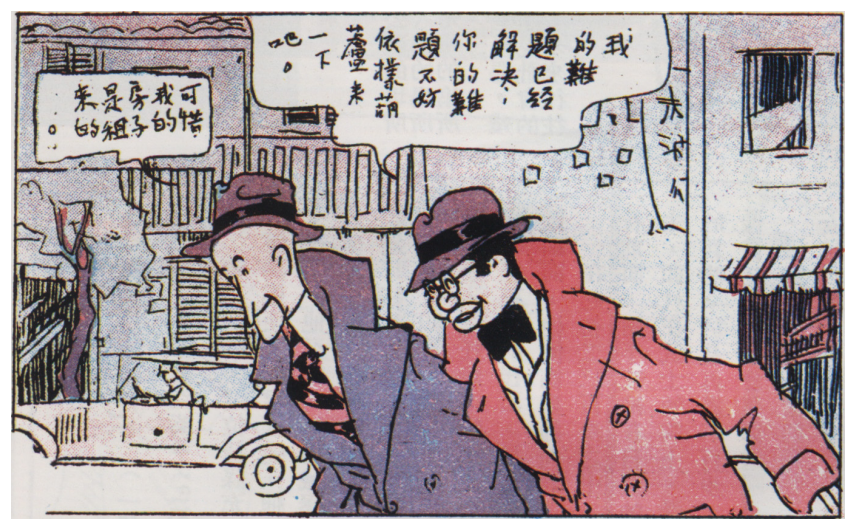

FIGURE 22. Mister Wang and Young Chen on the street in Shanghai. Shanghai Sketch, no. 42

(February 2, 1929).

movie posters, storefront displays, shop awnings, railway compartments, and late model automobiles (see figure 22).

Like its host magazine, Mister Wang attracted readers with its ongoing representations of everyday life in the modern treaty port city. The strip's little weekly dramas, steeped in the familiar minutiae of urban modernity, disappoint commentators looking to find therein a higher historical mission for China's manhua. In Mister Wang, one searches in vain for a national story of modern China's grand march through momentous, landmark events of struggle and resistance. Yet the lived reality of the modern constructed through Shanghai Sketch and its most famous comic strip helped city dwellers imagine and enact an alternative story, a shadow history bound to a space and time both close at hand and connected to a global narrative of life in the modern city. 